\title{
Derecho fundamental a la Seguridad Social en el ámbito de la Unión Europea*
}

\author{
Prof. Dr. Manuel M. ${ }^{\text {a }}$ Zorrilla Ruiz \\ Catedrático Emérito \\ Universidad de Deusto \\ Ex-Presidente del Tribunal Superior de Justicia del País Vasco \\ Presidente de la Asociación de Jueces y Magistrados Jubilados de España
}

\begin{abstract}
Resumen: La Constitución española de 1978 ha situado el régimen público de Seguridad Social bajo la tutela de un simple principio programático. Éste se habría elevado a la categoría de derecho fundamental si el Proyecto de Constitución europea hubiese recibido la ratificación unánime de todos los integrantes de la Unión Europea. Pese a ello, el Tratado de Ámsterdam y la versión más reciente del Tratado de Roma ofrecen poderosas razones para justificar el carácter de derecho fundamental que ostenta el derecho a la Seguridad Social. Tal cualificación tiene que propagarse a los respectivos ordenamientos jurídicos de cada país perteneciente a la Unión Europea.
\end{abstract}

Palabras clave: Seguridad Social, derecho fundamental, principio programático, Constitución europea, Unión Europea.

Abstract: The Spanish Constitution (1978) has placed the public system of the Social Security under the protection of a simple principle of law. It would have become a basic or fundamental right, if the European Constitution would have received the unanimous ratification of the members of the European Union. In spite of that, the Amsterdam Treaty and the most recent version of the Roma Treaty give powerful reasons to justify the nature of fundamental right which is own of the Social Security. This qualification must be diffused to the law prevailing in each country of the European Union.

Key words: Social Security, fundamental right, principle of law, European Constitution, European Union.

* El presente trabajo recoge las ideas expuestas en el estudio que, bajo el rótulo «Migraciones constitucionales del derecho a la Seguridad Social», ha aparecido, muy recientemente, en la Revista del Ministerio de Trabajo y Asuntos Sociales, Seguridad Social, n. ${ }^{\circ} 59$ pp. 75-92, y que aquí se publica con la explícita cita de su procedencia. No huelga anticipar, por vía orientadora, que la Constitución española de 29 de diciembre de 1978 se caracteriza por una ductilidad interpretativa que, como variante expresiva del valor superior del pluralismo político, resulta máximamente provechosa para el análisis y disección del tratamiento dado al derecho a la Seguridad Social por el legislador constituyente, y, no menos, para vislumbrar y/o sugerir las peripecias de uno de los denominados Principios rectores de la Política Social y Económica. Cabe invocar un uso alternativo legítimo de las normas constitucionales, gracias al que es factible atribuir al derecho a la acción protectora de la Seguridad Social la dimensión propia de los derechos innatos y 
Sumario: 1. Relevancia de la elasticidad constitucional para abordar el derecho a la Seguridad Social.-2. Vinculación y alcance pragmático del derecho a la Seguridad Social. - 3. Reflexión sobre la rúbrica que acoge el principio atinente a la Seguridad Social. - 4. Derecho fundamental a la tutela de la Seguridad Social. - 5. Renacimiento de una anterior doctrina. -6. Aplicación del principio de primacía del Derecho Comunitario.

\section{Relevancia de la elasticidad constitucional para abordar el derecho a la Seguridad Social}

Sorprenden mucho - por lo insistente y poco imaginativo de su reiteración - las propuestas que, ante las dificultades causadas por la lectura y el entendimiento de algunos pasajes constitucionales, tienden a eludir los esfuerzos interpretativos y prefieren las sugerencias de reforma, como si los principios y/o preceptos afectados - que, entre otros méritos, ofrecen el de una propensión comunicativa que alentó el ejercicio del consenso y los hábitos de elasticidad comprensiva - fuesen imperativos rígidos que responden al nombre de pan para hoy y hambre para mañana.

Cuantos, en esos trances, defienden una reforma mecanicistamente material y cómoda de la legalidad fundamental - modificando la dicción de un precepto concreto y expresando, en los términos que surgen de su corrección, otras proposiciones o conceptos - ignoran que la norma suprema del ordenamiento jurídico — si no se admite que, por encima de ella, están los valores superiores con que el constituyente la moraliza y desplaza del vértice de la clásica construcción piramidal del sistema de Derecho objetivo - contiene, a diferencia de otras cartas políticas menos origina-

merecedores de la más consistente dosis de tutela y efectividad. También es cierto que, como lo acreditan abundantes testimonio históricos, la doctrina de su engrandecimiento se ha visto frenada, desde la incoación de la crisis económica, por la hostilidad de las perversiones mundializadoras y la devoción suscitada por las prédicas del neoliberalismo. Tras el Tratado de Ámsterdam, la remisión que los textos recién consolidados hicieron a la antigua Carta Social y a la moderna Carta Comunitaria de la Europa creciente, dejaba fuera de duda la tesis de que, en ese espacio, el derecho a la Seguridad Social obtenía el reconocimiento de un derecho fundamental. Conclusión que, en virtud del principio de primacía del Derecho Comunitario, se imponía a los ordenamientos jurídicos de los Estados miembros de la Unión Europea. Consideración que prevalece una vez que, a falta de ratificación unánime, se haya salido - demasiado pronto-del carril la propuesta de Constitución europea, cuyo Tratado de establecimiento acogía aquel derecho en el elenco de los derechos fundamentales que fijaba. De ahí que, conforme a esa doctrina razonable y no obstante el fracaso de la iniciativa del constituyente europeo, subsista el deber - a cargo de los Estados miembros - de adecuar los sistemas o regímenes públicos de la Seguridad Social a las exigencias propias de un derecho fundamental que, como tal, reclama su resituación en el contexto del aparato constitucional. 
les, un reto de interpretación que es fruto de su particular ductilidad. Se consideran constituciones rígidas las que - hostiles a reducir el volumen ideológico de su depósito dogmático - exigen, para su reforma, requisitos de tales dificultad y envergadura que disuaden de sus aspiraciones a las corrientes ideológicas y/u opciones políticas - opuestas o contradictorias - que intentan devenir poderes públicos por las vías democráticas de la competencia electoral. El inmovilismo constitucional - más o menos inexpugnable, pero siempre agresivo - combate el ingreso de esas ideologías en el marco de un ordenamiento jurídico formado por la legalidad fundamental y el resto del Derecho objetivo que ha de serle fiel. La nota de la esencial enemistad que, pese a los disfraces cosméticos, concurre indefectiblemente en la confrontación política, inspira la falsa excelencia de las reformas rígidas constitucionales y endurece su filosofía de exterminio. Por constitución elástica se entiende, al contrario, la que dota de accesibilidad muy amplia al uso del procedimiento de reforma y facilita al adversario la oportunidad de convertirse en alternativa de legislación y de gobierno. Se inspira en la tesis de que - conforme a la grandeza y servidumbre de la democracia - los inconvenientes de una convivencia política, pródiga en incomodidades y fricciones, son preferibles al triunfalismo de la intransigencia constitucional. Ello permite - aun sin llegar, como último remedio, a la actualización de su espíritu móvil - variar su letra escrita y establecer las condiciones aptas para que el ámbito constitucional remozado se torne más acogedor y receptivo frente a las posiciones ideológicas que había proscrito de raíz.

Si el procedimiento de reforma de la ley fundamental del Reino de España se adaptase a una u otra de esas modalidades, se justificarían las reacciones que, ante ciertos obstáculos, propugnan la necesidad de introducir concepciones o valores necesitados de una modificación formal para obtener el ajuste deseado. Tampoco huelga recordar que, en nombre de la elasticidad constitucional, prolifera - como ajuste de cuentas o receta de compensación - una capacidad de desvarío que estremece las sensibilidades más abiertas, las conciencias de óptima capacidad perceptiva y los entendimientos más propensos a la cordura de la interlocución. Dicho lo cual, hay que elogiar la singularidad de una elasticidad elevada a la segunda potencia y consistente en promover - como hace el art. (artículo) 1.1 CE (Constitución española de 27.12.(9)78) - el pluralismo político a valor superior del ordenamiento jurídico. Las ventajas de esta elasticidad de alto voltaje suman una contribución, novedosa y eficiente, al procedimiento de reforma escrito en el tít. (título) X CE. Aportan una transformación propia de la cultura y el espíritu que erigieron el Estado social y democrático de Derecho, y robustecen el sentimiento constitucional o conciencia común - afín a la identificación con un yusnaturalismo existencial - de que la ley fundamental no ha vacilado en 
llevar al último confín las ofertas de cambio que las ideologías de compromiso más audaz tienen derecho - aunque esta afirmación se haga costosamente asimilable - a conseguir de los poderes públicos.

Es ello consecuencia de los usos alternativos de la legalidad fundamental que el legislador constituyente acomete como una opción tecnificada y más perfecta que la que, en lejanas circunstancias históricas, surgió a partir de un estado de excepción motivado por la denegación de las reformas legislativas y su acomodación a la cláusula de justicia material con que el art. 3 II CE (Constitución italiana de 27.12.(9)47) llamaba a las puertas de las conciencias morales de los Estados soberanos de Occidente. Estos usos alternativos corresponden al contenido esencial o espacio inviolable de la noción del pluralismo político y, lejos de enfrentarse al hecho constitucional y alzarse contra el ordenamiento jurídico que trae causa del mismo, ensayan y consumen las aplicaciones sensatas que la sagacidad de la interpretación hace factibles. No desautorizan los objetivos constitucionales ni ciegan los cauces que su discurso exige, sino que encienden su fertilidad ante la superveniencia de realidades sociales que, fuera de cualquier objeción, están ahí y hay que ponderar, porque, a falta de su aprehensión y de su análisis, el anhelo de hacer justicia humana es inviable.

Los usos alternativos legítimos de los preceptos y/o principios constitucionales, objeto de enfoques interpretativos divergentes, son conjuntos o series ordenadas de acciones - ligadas a las evidencias de la Historia y a las ofertas del pluralismo político- que, sin alterar un ápice la letra del texto constitucional, ejercitan la perspicacia necesaria para responder a lo que, como norma de comprobación e imperativo deontológico, explica la invocación que hace de ese valor el art. 1.1 CE. Se afirma que - ante el aumento, la mixtificación y la emergencia de disparidades o desencuentros ideológicos - los principios y preceptos constitucionales pueden recibirles hospitalariamente con interpretaciones o hallazgos normativos que -integrados en el ordenamiento jurídico o en sus complementos - no dependen de quién sabe qué ensayos de complacencia o prestidigitación hermenéuticas, sino que apelan, con solvencia y actitud receptiva, a uno de los varios entendimientos plausibles que satisfacen los intereses generales, excluyen las pretensiones de privilegio y producen efectos pacificadores. El legislador ordinario - responsable de estas tentativas en las parcelas del Derecho objetivo que amplifican los principios o preceptos constitucionales afectados - puede abordar, con la dosis de justicia material que tiene a su alcance, las cuestiones sobrevenidas - hasta entonces ignoradas e inéditas - que plantea la protección de los intereses generales, sin necesidad de sacrificar las impregnaciones ideológicas, que embebe la operación de legislar, ni de reformar la carta política para conseguirlo. 
De ahí, la calidad del pluralismo político que el art. 1.1 CE enaltece en un doble concepto. Pertenece a una norma de comprobación que añade a su factura jurídica la certidumbre histórica, avalada por las experiencias y episodios de la acción constituyente, de que el principio se formula - teniendo presente la utilidad pública y/o el interés común - para el bien de todos o alguno de los grupos sociales en que, como reza el art. 9.2 CE, se integra el individuo. Tan privilegiada presencia - justificante de la libertad que, al aunarse con la igualdad efectiva, sintetiza lo evidente de la justicia material - prueba las ventajas de que el pluralismo político procure entendimientos - sucesivamente actualizados - de la voluntad constituyente que nunca habrían penetrado en la órbita del Derecho constituido sin la incorporación fundamental de ese valor y la abundancia de oportunidades interpretativas que su recepción estimula. Como imperativo deontológico, el pluralismo político completa sus funciones de norma de comprobación y exige que las oportunidades de su puesta en escena se multipliquen y gestionen para afianzar la paz social - bien jurídico que, más adelante, suscita la mención del art. 10.1 CE - y evitar la ruptura del ordenamiento jurídico o las quiebras de su continuidad.

Las soluciones que - gracias a la prudencia requerida por el manejo del pluralismo político y al arrojo de las aventuras que desencadenaadopta el legislador ordinario, libre para reforzar y difundir sus legítimas tendencias ideológicas, revisten dos características. Una de tonalidad conservadora que, conforme a la lectura originalista del texto constitucional, no contradice su letra ni su espíritu y deja indemne su fidelidad vertical, si el desarrollo legislativo no ha planteado al respecto problemas de bulto y puede actuarse sin dificultades. Ello acontece cuando las realidades sociales no experimentan cambios sustanciales y basta el auxilio de los clásicos criterios de interpretación. No hay que echar mano del ritual procedimiento de reforma, si el acertado empleo de esos elementos - fiables y avalados por el buen fin de su utilización tradicional - permite que los problemas se resuelvan gracias a lo razonable de su mediación y no da lugar a que la metodología interpretativa pase a ser un problema necesitado de previas dilucidaciones. Estas acciones encajan en el marco de una tradición interpretativa que no encara mudanzas tan sobresalientes como las que, ante supuestos-límite, obligan al uso alternativo de la legalidad fundamental. Algo afín a la distinción que el Derecho Civil ha entablado entre la permanencia de la presuposición y la dislocación de la base del negocio jurídico. Hasta aquí, la significación conservadora que el pluralismo político concilia con una libertad hermenéutica equilibrada y consecuente con los criterios observados de antiguo para esclarecer el sentido de las normas jurídicas ininteligibles o confusas. 
El uso alternativo constitucional -más intrépido y no necesariamente rupturista - adquiere un significado divergente, notoriamente polémico y sustitutivo de las soluciones que, sin responder a cambios sustanciales, se daban por buenas y no engendraban dudas de dificultad reconocida. Lo vidrioso de optar por esta metodología es decidir si verdaderamente se han franqueado los límites que separan las viejas realidades sociales, caducas u superadas, de las nuevas, vigentes y superadoras, que les han sucedido - porque, sin tratarse de un accidente reversible, sobreviene un cambio sustancial, exigente de la variación del sentido de una norma constitucional o de la exhumación de un principio antes latente y ahora imprescindible - y si las demandas sociales o los lances motores del cambio - lejos de parecer voluntaristas o aberrantes, que es tanto como adversarios de lo justo- aportan novedades que conmueven la recta razón y la urgen a revisar la suficiencia o el acierto de las soluciones frecuentadas hasta entonces. Juega un papel de primera magnitud el dictamen, no pervertido ni transmutado en un falso mensaje, de la opinión pública ilustrada - esto es, no extraviada ni cautiva de consignas sectarias - y capaz de percibir, con sensibilidad y tino, la cantidad y calidad de los hechos sociales que se someten a su juicio.

El valor superior del pluralismo político - cuya fisonomía bifronte explica su racionalidad democrática y apoya eficazmente las interpretaciones constitucionales - autoriza usos alternativos de los principios y preceptos de la legalidad fundamental, dentro y nunca al margen - precisión necesaria para disipar las zozobras del uso alternativo revolucionario - del elenco de salidas interpretativas con que, al precio de alguna que otra condescedencia menor, el constituyente apuntala la idea de la preservación de las esencias constitucionales y evita situaciones de crisis que erosionen la dignidad de aquel valor. El análisis del art. 1.1 CE - que, para destacar la generosidad de su propósito, entremezcla el género con las especies y subespecies de los valores superiores - revela que el pluralismo político es una manifestación de la libertad efectiva y no el ornato de tentativas teñidas de falso progresismo. Libertad que - efectivamente aglutinada con la igualdad de todos - genera la síntesis de la justicia material que los poderes públicos han de garantizar y difundir, regulando sus condiciones de perpetuación o despejando los estorbos que la paralizan.

El provecho de lo reflexionado favorece el trabajo de las interpretaciones sugeridas por la lectura natural de un precepto tan meridiano como el art. $41 \mathrm{CE}$-que figura bajo el rótulo De los principios rectores de la Política Social y Económica - y por la relectura evolutiva que deriva del tránsito histórico, en el curso de cuyas procelosas aguas navegó el legislador constituyente, de un Derecho de la Seguridad Social de la prosperidad a un Derecho de la Seguridad Social de la crisis - lastrada con demasiados adjetivos - que, paso a paso, mina los adelantos del Estado de Bienestar 
- seriamente tocado del ala - y predispone sicológicamente a los temibles episodios de su disolución. No en vano y por desgracia, las más altas instancias interpretativas insinuaron, para estremecimiento general de la comunidad, la eventualidad de una Seguridad Social cuasibenéfica, en que las relaciones de protección asistenciales fuesen la regla general y las contributivas la excepción. Condimentación aderezada con un concepto de solidaridad ligado a la más castiza metodología demagógica y hostil al rigor científico con que las categorías de esta parte del Derecho Social han de abordarse.

El cuerpo del razonamiento - para el que lo dicho parece aprovechable - comienza parando la atención en algunos aspectos concernientes a la naturaleza y condición del derecho a la Seguridad Social, que el cap. $3 .^{\circ}$, tít. I CE rebaja a la cualidad que le otorga el rótulo denominado De los principios rectores de la Política Social y Económica.

\section{Vinculación y alcance programático del derecho a la Seguridad Social}

$\mathrm{El}$ art. $41 \mathrm{CE}$ enuncia uno de los principios capitales que, literalmente incorporados a la carta política y no extraídos de su texto mediante operaciones lógicodeductivas, carecen de la eficacia preceptiva directa que el art. 53.1 CE reduce - a causa de su naturaleza vinculante para cuantos poderes públicos les ponen al servicio de los intereses generales - a los mandatos y/o prohibiciones que reconocen - gracias al deber de no obstaculizar lo indiscutible de su atribución y ejercicio-o garantizan - asegurando los cambios inherentes a su reconocimiento- los derechos y libertades de uno u otro rango. La dicción del art. 53.3 CE - que declara la condición orientadora o meramente directiva del citado principio- obsta a cualesquiera petrificaciones que, contra las reacciones interpretativas avaladas por el valor superior del pluralismo político, hagan de aquél una consigna cuya naturaleza programática se empobrece - sin fruto alguno y por tiempo indefinido - si no es objeto del desarrollo legislativo que requiere. Ello esteriliza - con detrimento de la causa de la plenitud del ordenamiento jurídico - sus propósitos y su significado. Se trata de una norma que, para no consolidar la inconstitucionalidad por omisión debida a los retrasos del legislador ordinario, segrega un mecanismo sancionador implícito que mueve a reflexión. Su dispositivo interviene al cundir el convencimiento irrevocable de que - alejándose del mandato constitucional y sin dar señales de ir en busca del tiempo perdido - el legislador aparca las obligaciones de despliegue de alguno o algunos de los principios estampados en el cap. $3 .^{\circ}$, tít. I CE y, con su abstención, deja heridos de muerte unos valores vitales cuyas expectativas se difuminan o perecen. Aun cuando no 
sea éste uno de los riesgos que - ostensiblemente y por ahora- aquejen globalmente al art. $41 \mathrm{CE}$, conviene apuntar la reserva de un mecanismo eficaz que, en su momento, localice y pondere las realidades sociales que obedecen a las nuevas exigencias del principio rector y que, a causa del olvido legislativo, justifican lo inexcusable de un modelo de sanción subsidiaria.

La razón de ser de la distinción - que atañe a las nociones de eficacia preceptiva directa y alcance escuetamente programático - comulgaba con la tesis de que, mientras la naturaleza y estructura de los derechos y libertades constitucionales no impedían su tutela - efectiva e inmediata - por los poderes públicos que aplicaban las normas declarativas de su existencia previa y condición innata, los Principios rectores de la Política Social y Económica - adjetivos inseparables, ambos - requerían una implementación técnica, sin la que su desarrollo legislativo era inviable o, en caso de intentarse, fracasaba a la primera de cambio. Si la holganza o el retraso del legislador en desarrollar exhaustivamenteo los principios, incitaba - como jurídicamente se intuía y era preciso para evitar su reducción a letra muerta- a construir y ejercitar funciones vicarias de sustitución de la inactividad legislativa, cabían dos opciones, respectivamente posibilista y pesimista, que, aunque imprescindibles, no gozaban de la calidad de los medios con que la Política Legislativa o la ciencia de la legislación habrían cumplido sus cargas de implementación. $\mathrm{O}$ bien otro de los poderes públicos - con todas las de perder, el Poder Judicial - aplicaba directamente el principio marginado por el legislador ordinario, siempre y cuando lo permitieran la sencillez de su figura rectora y la ausencia de condicionamientos extrajurídicos que la jurisdicción no podía sustituir ni completar. El art. 5.1 LOPJ (Ley Orgánica del Poder Judicial de 1.07.(9)85) muestra cómo - comprobado que, al cabo de un tiempo razonable, se ha incumplido la cláusula del art. 53.3 CE y que la demora en legislar es digna de reprobación- el legislador, desarrollando aspectos aconsejables del mandato del art. 122.1 CE, asigna a los principios rectores de la Política Social y Económica la vinculación o eficacia preceptiva directa que resulta de reinterpretar evolutivamente - rectificándola como conviene al caso - su calificación inicial. O bien lo insalvable de las dificultades opuestas por la inactividad legislativa, desvirtuaba y abolía el mensaje del principio afectado. Le rebajaba a una norma desprovista de valor vital, inútil para amparar los intereses de una sociedad pluralista que, fiando en la credibilidad de su mensaje, tenía todo el derecho del mundo a denunciar la frustración sufrida y a exigir un subrogado o sustitutivo judicial de la protección de los bienes de vida que los legisladores le rehusaban.

La línea de fuerza de este pensamiento parece haber calado en la creatividad del ordenamiento jurídico que - a imitación del personaje de la comedia clásica y castigándose a sí mismo por el reproche de la mala 
conciencia de sus demoras u omisiones - entiende que hay normas principalistas y no preceptivas del texto constitucional que, al cabo de un tiempo más que respetable, no se han desenvuelto, con la amplitud y diligencia requeridas, y aumentan los peligros de ampliación del vacío de las lagunas desigualitarias. Ahí naufragan las colectividades o los grupos sociales portadores de legítimas aspiraciones, cuya naturaleza de origen - la peculiar de un interés desnudo - propende a transmutarse en otra - específica de un interés vestido mediante acciones procesales - que sumerge a sus componentes en situaciones jurídicas, satisfactoriamente protegidas, o les atribuye los derechos subjetivos que adquieren como miembros de la comunidad en que racionalmente organizan. Aunque - más instintiva que reflexivamente - se haya llegado a sostener que la sujeción de todos - ciudadanos y poderes públicos - a los imperativos constitucionales y al resto del ordenamiento jurídico, entraña la generalización del efecto directo en el art. 9.1 CE, la conclusión es técnicamente discutible, porque la meridiana distinción - que el art. 53.1 y 3 CE ha fijado - entre lo vinculante y lo simplemente orientador, desestabiliza este prejuicio.

Convencido, no obstante, de que el completo y correcto desarrollo de los principios del cap. 3. ${ }^{\circ}$, tít. I CE es, al menos en parte, una asignatura pendiente, el art. 5.1 LOPJ declara que todos los preceptos de la carta política adquieren eficacia vinculante, porque -como se colige entre líneas - ha transcurrido un espacio de tiempo cuya larga duración desaconseja prolongar la espera en perjuicio de la ciudadanía perjudicada por semejantes dilaciones. El art. 5.1 LOPJ entiende que ha mudado la presuposición - latente en el contraste del art. 53.1 y $3 \mathrm{CE}$ - o pronóstico favorable al agotamiento, en ese tiempo, de las previsiones programáticas y, ante la intimidación del vacío, confía a la jurisdicción la carga de facilitar - en lo posible y usando acaso de instrumentos mellados - el cumplimiento de los compromisos que el legislador había contraído con unos principios rectores que acusan la indigencia de su realización. Se está ante una variante de la acción transformadora que, según el art. 9.2 CE, corresponde a los poderes públicos, bien asumiendo las obligaciones naturales nacidas en tales circunstancias, bien - como aquí se estima - a través de un mandato legislativo que - ante la lesiva realidad históricosocial de la desidia del legislador y acreditada su incidencia en la reinterpretación del art. 53.1 CE - convierte al Poder Judicial en el cuasilegislador forzoso que ha de poner música a un libreto huérfano de la esperada partitura.

Los más recientes esfuerzos normativos de reforma apelan — con cierta indulgencia - al concepto de insuficiencia legislativa para remediar un vicio que la LOTC (Ley Orgánica del Tribunal Constitucional de 3.10.(9)79 no tuvo a bien considerar, pese al canon - que sanciona el art. 9.3 CE - de responsabilidad de -todos, sin excepción-los poderes públicos. 
En las actuales circunstancias, el art. 53.3 CE se completa con un ingrediente equitativo que data del encarecimiento del art. 9.2 CE. Significa que, si la inconstitucionalidad por omisión no se corrige al cabo de un tiempo suficientemente revelador de la irreversibilidad de la laguna que perdura, la jurisdicción ordinaria y los demás aplicadores de los principios no desarrollados han de tratarlos como normas dotadas de eficacia preceptiva directa. La sujeción de todos al ordenamiento jurídico - que, con alcance general, proclama el art. 9.1 CE y aquí cobra un significado muy enfático - incluye la enérgica destrucción de los obstáculos que impiden convertir un principio hibernado en los mandatos o prohibiciones que, según la naturaleza de las cosas, son el eco una demanda social de justicia que clama por su satisfacción.

A la hora de atribuir a esos principios el efecto directo con que se sancionan la holganza del legislador y la falta de un tempestivo desarrollo, no todos dan - usando de un giro coloquial-facilidades para que los jueces ordinarios los apliquen con comodidad o incluso puedan aplicarlos. La estructura de una norma orientadora o programática se resiente, a veces, de dificultades que frenan el ritmo de estas operaciones, porque su destinatario - natural e inmediato - era el legislador que se ha olvidado de ella y no el juzgador que, de buenas a primeras, se encuentra con los apremios de hacerla entrar en juego. Es preciso que - para su aplicación mínimamente aseada - consten claramente los sujetos activos de la situación jurídica, a los que se asignan potestades o deberes, que se describan comprensivamente las conductas que forman la figura rectora del principio, sin perjuicio de su ductilidad interpretativa, y que no se requieran actividades o complementos técnicos que la jurisdicción no puede suplir con los frágiles medios que están en su activo. Las novedades tecnológicas, económicas y sociales pueden hacen del deber implantado en el art. 1.8 C.c. (Código Civil español de 24.07.(8)89) una carga fatigosamente asumible y cara de soportar.

La oportunidad de la interpretación judicial del art. $41 \mathrm{CE}$ depende de la importancia que, amén de otros pormenores históricos, proyecta - sobre la letra y el espíritu de su principio rector - una distinción central, definidora de la sustancia y los accidentes que contribuyen a centrar el concepto y aderezos del derecho a la Seguridad Social. Hubo una Seguridad Social de la prosperidad - en que se constituyeron e iniciaron su marcha de aproximación los efectivos del Estado Social y democrático de Derecho- y una Seguridad Social de la crisis, estigmatizada por las deserciones que, tan sutil como perversamente, causan las demasías de una flexibilidad inicialmente aceptable y su degeneración en una enfermedad asoladora. Una calamidad contemporánea que debe su expansión a la prédica de las proclamas neoliberales y al cortejo de embustes dialécticos que, con terquedad digna de mejor causa, jalonan las etapas de su proceso 
de conquista. Envuelto, todo ello, en los interrogantes de la moralidad y modernidad de la mundialización, que acaso - quiéranlo así los tiempos inmediatos y la Historia que va dar cuenta de ello - esté a punto de sufrir la prueba de fuego de la enigmática Europa social que, como una tercera vía de esperanza, se parece al oscuro objeto de un deseo esfumado demasiadas veces.

Vierten sus lágrimas, a la vuelta de la esquina, los eufóricamente confiados y defraudados luego por la sorprendente fenomenología que impide la unanimidad de las ratificaciones - a cargo de los Estados miembros de la UE - del, entre otros preceptos, art. 94 TCUE (Tratado por el que se establece una Constitución para Europa), que instala los intereses propios de la Seguridad Social en el marco de los derechos fundamentales. Calificación que sirvió de muy poco a la magra ilustración con que -al elogiar y promover el texto hoy estancado - los sindicatos del primero de los Estados soberanos que, acudiendo a la consulta popular, planteó y obtuvo la ratificación, demostraron ignorar supinamente y no explotaron, con el rigor debido, dicha novedad, pasando de reflexionar - con la mínima detención didáctica- sobre la importancia de sus consecuencias y limitándose a aplaudir la tosquedad informativa de la propaganda gubernamental.

Son dos los rasgos distintivos que asisten a los principios rectores de que se hace cuestión. Uno, el de merecer su inserción en un pasaje constitucional que, al definirlos descriptivamente o respecto a nociones ya sabidas, les asigna su rotulación nominativa. Ello les diferencia de los principios constitucionales que, aun figurando en afirmaciones de pasada, no pierden su condición de tales - es el caso de la alusión del art. 16 CE a la necesidad de respetar el orden público protegido por la ley - o que, como criterios informadores, nacen de reflexiones interpretativas o procesos de destilación que operan sobre los preceptos o parcelas de la legalidad fundamental. Los principios rectores modelan genéricamente las conductas o anticipan los pasos que ha de dar el legislador para ordenar aspectos preferentemente atractivos del contenido esencial o zona inviolable de los derechos que el art. 10.1 y las secs. (secciones) 1..$^{\mathrm{a}}$ y $2 .^{\mathrm{a}}$, cap. (capítulo) 2. ${ }^{\circ}$, tít. I CE entienden anteriores y superiores a las leyes humanas positivas. Amén de los deberes generales de reconstituir y mejorar las manifestaciones de ese acervo intangible, el legislador ordinario se ve atado, conservando sus márgenes de decisionismo político, por las ligaduras de unos principios rectores que -es ésta una afirmación capital - pueden resituarse, sin objeciones doctrinales de peso, a seguido del emplazamiento que de cada derecho constitucional hace el precepto que le reconoce. Ello permitiría vaciar el cap. 3 . $^{\circ}$, tít. I CE y redistribuir sus principios - como especialidades caracterizadas por su calidad estimulante - en aquellos pasajes que incluyen los derechos cuasinaturales y a los que el art. 53.1 CE atribuye eficacia preceptiva directa. 
Llevando el discurso al art. $41 \mathrm{CE}$, susceptible de interpretaciones alternativas, la promesa del régimen público de Seguridad Social - que ahí se profiere - forma parte del núcleo invulnerable de unos cuantos derechos constitucionales reafirmados con anterioridad. En ese principio se dan cita y convergen la custodia de los derechos fundamentales a la vida $y$ la integridad física, que acoge el art. $15 \mathrm{CE}$, a la seguridad de que se ocupa el art. 17.1 CE - donde no sólo acampan las variantes de la seguridad individual, sino también las de la seguridad social y colectiva que ha encumbrado el Estado de Bienestar - y a la remuneración del trabajo prestado, según el art. 35.1 CE, que incide en la suficiencia de las prestaciones sociales, así como a no pocas de las funciones sociales de la libertad de empre$s a$ amparada en el art. $38 \mathrm{CE}$. Las relaciones de protección que origina el funcionamiento del sistema son, con independencia de sus particularidades técnicas, emanaciones o reflejos de dicho núcleo invulnerable.

\section{Reflexión sobre la rúbrica que acoge el principio atinente a la Seguridad Social}

Ante el llamamiento del art. $41 \mathrm{CE}$, se pregunta por la coherencia de la rúbrica - a saber, De los principios rectores de la Política Social y Económica - que abandera las proposiciones directivas del cap. . $^{\circ}$, tít I CE. Hecha también la salvedad - que despierta curiosidad y asombro - de que, ¿deliberadamente o por descuido?, el constituyente, que, en el art. 53.3 CE, ha prejuzgado el carácter de principios de esas proclamaciones añade, no obstante, los reconocimientos de derechos - a la protección de la salud, a la cultura, al medio ambiente adecuado y a la vivienda - que enuncian los arts. 43, 44.1, 45.1 y 47 I CE. Pese a una rotulación que cuesta atribuir a simple inadvertencia, el art. 53.3 CE, que predice el futuro de los principios rectores a que se refiere, guarda silencio acerca de la suerte - que no tiene por qué ser la misma - de los derechos contemplados en aquel pasaje y fuera del ámbito que el cap. $2{ }^{\circ} \mathrm{CE}$ reserva al reconocimiento y, en su caso, a la definición de los derechos y libertades en general.

Todo principio tiende a forjar iniciativas - muy varias - que presuponen un ejercicio de razonabilidad inteligente desplegado por cuantos, fieles a sus orientaciones, intentan materializar - con dificultad indiscutible - los criterios que imparten. Un principio precede a la ejecución o el cumplimiento de los objetivos deseables que - figurando en sus programas - quieren lograrse con prontitud e integridad. El principio del art. $41 \mathrm{CE}$ es, ante todo, informador, porque esta cualidad - consistente en dar forma sustancial a las cosas - pertenece a la alcurnia de los principios generales del Derecho y - al implantarse el sistema de fuentes del Derecho objetivo, luego 
perfeccionado en el art. 5.1 LOPJ - el art. 1.4 C.c., consciente de su impacto políticolegislativo, no ha dejado pasar la oportunidad de acentuarla. La información del ordenamiento jurídico - que debe producirse - reside en la elección, prudente y acertada, de una o varias zonas del interés general -rectius, de uno o varios de los intereses generales conexos o enlazados - que forman parte de las aspiraciones legítimas de un grupo social, pero que -como materia, en sentido filosófico, o bien de producción, en sentido económico, no transformados por la forma que les individualiza y diferencia - requieren la vestidura de un principio informador cuya anquilosis - por inmovilidad creativa - es pésimo ejemplo y causa de descrédito. Experiencia que, haciéndose eco de ese precedente, recoge el art. 53.3 CE cuando declara que los principios informarán la legislación positiva. Su desatención no es un incumplimiento trivial o secundario, sino un atentado frontal contra la Política Legislativa o ciencia de la legislación, tanto si proviene de agresiones intencionales del legislador, cuanto si nace de dilaciones injustificadas o descuidos que ejemplifican la inconstitucionalidad por omisión. Valga, en todo caso, recordar el papel que, en el futuro, puede desempeñar la insuficiencia legislativa de que se ha hecho mérito.

El principio del art. $41 \mathrm{CE}$ tiene de informador sus caracteres de pretensión universal y de derecho innato que, indivisiblemente, surgen al calor del Estado social y democrático de Derecho. Anticipando ideas dignas de reflexión más densa, la oportunidad de un principio informador se advierte cuando la naturaleza de las cosas - minimizada, en ocasiones, como si no fuese la clave y el cauce de la recurrencia a las verdades del orden natural- obliga a concretar un pensamiento que asume dos funciones históricas. Una, la de alzar el velo y desenmascarar la falsa modestia con que los regímenes autoritarios más crudos - no escuetamente paternalistas - se arrogaron las conquistas de un Estado de bienestar adulterado por preferencias político-económicas e insensible a las necesidades de su cualidad antropocéntrica. Otra, la tentativa, más o menos accesible, de reparar la deuda histórica - que no es algo difuso y escondido tras el populismo de sus advocaciones pintorescas - nacida de la obcecada indiferencia del Estado demoliberal frente a los retos del futuro de la persona humana - uno de los aspectos eminentes y atractivos de su dignidad - y de su concepción como un bien colectivamente defendible, cuyos episodios de desmerecimiento justificaban el derecho a obtener la reparación del daño sufrido.

La cualidad de principio rector que, por designio explícito del constituyente, conviene al art. $41 \mathrm{CE}$, presenta una significación hacendosa que excede de lo solemne y filosófico de su función informadora. El art. 9.2 CE se sirve del verbo corresponder para asignar, sin afán exahustivo, a los poderes públicos - noción omnicomprensiva y más extensa que la de los tres poderes clásicos - la toma de decisiones generales y las acciones especiales de 
transformación fundadas - según un criterio importado de la teoría marxista del Derecho y, ello no obstante, valedero- en la idea de que las normas componentes del ordenamiento jurídico no sólo se destinan a resolver conflictos y a pacificar la vida social, sino también a planificar y consumar una nueva especie de revolución - a saber, la revolución interior - que, según la grandeza y la pluralidad de los fines, cambie discretamente el rostro de las sociedades, le reforme muy visiblemente o le haga irreconocible de futuro. La iniciativa de esos poderes completará, unas veces y dentro de sus atribuciones, las mudanzas consistentes en el cumplimiento - irretractable y espontáneode obligaciones naturales innominadas que sientan las bases del proceso de cambio. Otras, los principios rectores de que forma parte el art. $41 \mathrm{CE}$, cuidan de introducir - obedeciendo a la llamada del art. 9.2 CE - orientaciones y promesas cuyo imperioso cumplimiento acredite, tras estamparse en negro sobre blanco, las innovaciones que afectan a las instituciones predilectas del cap. 3 . $^{\circ}$ tít. I CE.

Regir es algo más activo y contundente que informar. El papel informador designa - con conocido alcance filosófico - lo que, aplicado a la materia o sustancia de un bien preexistente, provoca las individualizaciones que hacen de él lo que se pretende que sea y no algo distinto de lo buscado con la transformación a que se le somete. La función rectora presupone el éxito - previo y manifiesto en el buen fin-del ejercicio informador, pues le incumbe desenvolver las operaciones y dar los pasos que, sin falsa apariencia ni retraso, completan el resultado intelectual de una información impecablemente consumada. El mensaje del art. $41 \mathrm{CE}$ se enfoca desde una perspectiva general y compatible con los entendimientos sucesivos que, a la luz, de las realidades sociales, consiente su formulación.

Tras estas precisiones que separan lo informador — más bien estático y aleccionador - de lo rector, dirigido a generar los cambios en corto y por derecho, es claro que el principio animador de la proposición orientadora o directiva del art. $41 \mathrm{CE}$ atañe a una Política determinada. La suma de las Políticas que, de acuerdo con las conveniencias o los imperativos históricos, adoptan los poderes públicos, debe, aunque sólo consiga una aproximación o emparejamiento, satisfacer el máximo accesible de los intereses generales, porque su totalidad equivale a un bien común cuya modernidad secular - heredera de la tradición aristotélicotomista - es la propia del bienestar general consistente en los requerimientos de la coexistencia, la colaboración y la participación. Esta ambiciosa idea llevó a la implantación de un sistema de Seguridad Social que no aclamaba derechos colectivos - masivamente atribuidos a una supuesta comunidad erigida en titular de los mismos - y predicaba de todas las personas físicas - inmersas en los grupos de la sociedad pluralista-derechos individuales conexos con esas afecciones y con la frecuencia de los menoscabos a que su indemnidad 
quedaba expuesta. La Política, informada y regida por el principio subyacente al art. $41 \mathrm{CE}$, representa una de las especies elegibles por el Estado social y democrático de Derecho para colmar los espacios vacíos o menos poblados de una sociedad que, adiestrándose en las prácticas liberadoras de ese bienestar, se emancipa a medida que gana en madurez, celeridad y exactitud de diagnóstico para separar la paja del trigo, inventariar sus bienes y sus males, y encontrar los remedios dirigidos al engrandecimiento de los unos y el empequeñecimiento de los otros.

$\mathrm{Si}$, en vez de encomendar su hallazgo a la lucidez deductiva del intérprete, el constituyente cita nominativamente - para que no subsista duda alguna - la Política que el cap. 3. ${ }^{\circ}$, tít. I CE hace suya, es porque ha resuelto legar un testimonio de trascendencia histórica, aunque no responda de su cumplimiento por la posteridad a la que se ha cursado. Allí hasta donde cala la hondura de su compromiso, porque de otras Políticas no se ocupa tan minuciosamente, se apropia la grandeza y servidumbre de un afán novedoso que, sin perjuicio de atrevidas elecciones futuras, define los mínimos de su elenco de fidelidades a la claúsula transformadora y social del art. 9.2 CE, y el alcance de la deuda contraída con el espíritu de cambio. Esa Política trasluce la proclamación que de sus alternativas pluralistas hace el art. 1.1. CE, tanto para esbozar flexiblemente las vías de la transformación, como para evocar - con la solemnidad de un dogma indeleble - el amplio espectro del hecho constitucional y suprimir las trabas opuestas a su efectividad.

Se tiene, de entrada, la impresión de que tales principios - sin excluir el anunciado por el art. $41 \mathrm{CE}$ - definen y auspician Políticas disyuntivamente sociales o económicas, siendo así que el examen de la rúbrica que les conglomera conduce a conclusión distinta. En primer lugar, los principios que se ocupan de la Política Económica - conjunto somero, de previsiones ordenadas sobre los contenidos que la delimitan - no figuran ahí, sino en el tít. VII CE, denominado Economía y Hacienda. Parece pecar de asistemática una distribución que ha situado bajo dicho encabezamiento los principios centrales y relegado otros - también concernientes a la Economía - al cap.3. ${ }^{\circ}$, tít. I CE. Más coherente y armónico es defender que, en este pasaje, el constituyente no establece principios que, unas veces, se predican de la Política Social y, otras, de la Política Económica, pues, de alimentar un propósito diferenciador, su encabezamiento rezaría de modo más comprensible e inequívoco. Aludiría a sendas Políticas, cada una de las cuales operaría, por separado y por su cuenta, en uno de ambos campos. Una exégesis cuerda de la rotulación sugiere que los principios en cuestión atañen a Políticas que, avaladas por las respectivas proposiciones tutelares, son, simultánea e inseparablemente, sociales y económicas, porque una revisión - aseada y total - de su contexto ratifica la indivisibilidad y el carácter bifronte de las funciones que se les confían. 
Enfocando, para comenzar, la esencia y el sentido de la Política Social, su diseño ya no es el que de antiguo la equiparaba a la promoción de la justicia social en las relaciones de empleo dependiente y en el resto de los beneficios que el Estado de Bienestar deparaba a la causa de la clase trabajadora. Los mensajes de los textos fundacionales europeos han respetado la nominación originaria, aunque - gradual y lentamente - han añadido las nociones de espacio social y cohesión social para confesar la cautela y el fraccionamiento con que se presta audiencia a sus demandas. La rapidez del espíritu de cambio y los imperativos del pluralismo social desautorizan que hoy sólo se hable de una Política Social - con el alcance poseído desde sus orígenes - y no de las diversas Políticas Sociales, cada una de las cuales propende a transformar las comunidades - en que, a la luz del art. 9.2 CE, se integran las personas físicas - y los grupos que aquellos principios rectores contemplan. La parcela de la Política Social que brota del principio del art. $41 \mathrm{CE}$ ha dejado de ser, a la clásica usanza, la única de las Políticas Sociales imaginables y factibles, y se ha erigido en una de las varias Politicas Sociales - la más tradicional y cultivada, si se quiere - que amparan los intereses generales de los grupos refundidos o aglutinados en la sociedad, los de los literalmente preferidos por el constituyente, y, en fin, los de cuantos se adhieren a los ciclos de reconstrucción y crecimiento que acusan los signos de los tiempos.

Los derechos individuales de corte clásico - inherentes a la estructura y objetivos del Estado de Derecho liberal burgués - sólo requerían la ausencia de trabas excesivas para que sus titulares, libres de entorpecimientos, los ejercitasen con los recursos a su alcance y sin la mediación cooperativa o el refuerzo de los poderes públicos Los derechos sociales - producto de la vestidura que de los intereses desnudos hizo el Estado social y democrático de Derecho - reclaman el aditivo de la implementación económica y técnica, pues es imposible agotar su provecho a falta de un ingrediente que asegure su realidad - algo más que su existencia desvaída o platónica- y su efectividad, equivalente a un cambio superador de la escueta eficacia. Parece tautológico añadir a la denominación de las Políticas Sociales el calificativo de Económicas, pues la socialidad constituye un concepto sintético que, por sí solo, embebe el economicismo de unas soluciones inviables sin haberse previsto, con la prudente antelación, la naturaleza y magnitud de las necesidades, las preferencias aptas para su racional satisfacción y el volumen de recursos dables para conseguirlo. El cap. 3. ${ }^{\circ}$, tít. I CE quiere, aún así, dejar fuera de duda que cada una de las Políticas que sus principios insinúan, es, siempre y en todo lugar, una Política Social. Preconiza, con intencionalidad muy enfática, el servicio de los intereses generales de los grupos de la sociedad pluralista más necesitados de atención y en la urgencia de cuyas revoluciones interiores hay que insistir sin tregua. Cierto 
que una lectura evolutiva del art. $41 \mathrm{CE}$ atisba el riesgo de la suerte minimalista de estas transformaciones, al descubrir el verdadero rostro de una decadencia activada por el hecho globalizador y por la irrupción — voraz e inmisericorde - de las ideas y las prácticas neoliberales. Viene a cuento la anécdota - expresiva de una muy grande miseria moral - de la conversación habida por un político de pro que, para mayor afrenta de la causa de los desheredados del mundo, invitaba a otro hombre público - contagiado de inquietudes sociales - a desdeñar estas preocupaciones, como quien se libra de una trasnochada obsesión, porque, según la crueldad de su diagnóstico, los pobres - que formaban parte de una Historia sólo buena para ser olvidada - habían perdido la última batalla y estaban irremisiblemente derrotados.

La mención - conceptualmente superabundante- del carácter económico inseparable de la cualificación social de cada una de las Políticas que acopia el cap. 3 . $^{\circ}$, tít. I CE, supone también otro objetivo. A saber, el de que - si, en los demás campos, las dificultades económicas constituyen impedimentos aceptables para desviar o suspender el acondicionamiento y la mejora de los derechos o principios en cuestión - los reparos economicistas no cuentan al tiempo de rehusar o restringir, sin causa razonable y justa, las operaciones expansivas que la fuerza de los principios informadores y rectores reivindica con galopante intensidad. Ahora bien, como una cosa es la consigna general del espíritu de cambio - patente en el art. 9.2 CE - y otra la selección no controlable de sus contenidos y objetivos, los peligros de la inconstitucionalidad por omisión - resistente a las tentativas de ponerle fin - representan una dificultad mayor que los inconvenientes de aquella supeditación y de los episodios en que se concreta.

\section{Derecho fundamental a la tutela de la Seguridad Social}

Hay que reparar en la teoría - cuya agudeza no ha prevalecido- según la que el derecho fundamental a la seguridad de todos, recogido en el art. 17.1 CE, disponía de un contenido esencial o núcleo invulnerable que abarcaba el haz de intereses generales protegidos por el régimen público de Seguridad Social. El viejo mundo industrial y, a escala suya, las relaciones de trabajo que lo componían, incitaron a conjeturas estadísticas que, para obtener conclusiones provechosas, sopesaban la constancia de los riesgos relativos a la indemnidad física de los trabajadores y la frecuencia - no escasa- con que acontecían. Riesgos que, sin aparejar acaecimientos rigurosamente cíclicos o regularmente reiterados, exigían previsiones al servicio del interés - general e irrenunciable - en impedir, aliviar o poner fin a los daños, personales y reales, derivados del ejercicio de la actividad 
profesional por cuenta ajena. Partiendo de esta idea germinal, el derecho a los beneficios de la Seguridad Social comparte el acervo de bienes que el Derecho asocia a los derechos fundamentales - a que aluden los arts. 15 y $17.1 \mathrm{CE}$ - a la vida, la integridad física y la seguridad de las personas. Se consolida la experiencia - fruto de una Política Legislativa que, para combatir el miedo al vacío, prefiere las superposiciones inteligibles a las lagunas desorientadoras - de una misma norma jurídica distribuida en dos o más preceptos cuya cointegración garantiza la dosis de tutela adecuada al interés que se protege.

De aceptarse la tesis expuesta, que cuenta con los avales de una ocurrencia inteligente, el art. $41 \mathrm{CE}$ no se ha limitado a declarar la subsistencia de un régimen público de Seguridad Social que, de una parte, se garantiza - lo que entraña una obligación estatal más intensa que el reconocimiento de su imperio- y que, de otra, se relega a un pasaje inconsecuente con los valores que el Estado social y democrático de Derecho le asigna desde sus orígenes. $\mathrm{El}$ art. $41 \mathrm{CE}$ sobrevive como norma de acción que requiere elegir y aplicar, con urgencia, los aspectos inéditos del contenido esencial de los arts. 15 y 17.1 CE, que pertenecen a ese estado de cosas y encarnan las situaciones de necesidad correspondientes. Ello cabe sin obstar, lo más mínimo, a la naturaleza de derecho fundamental que, según esa sugestiva lectura, presenta el derecho a la Seguridad Social, ni ser el único reducto constitucional que invita a ocupar el espacio habitable que así se acrecienta.

Para paliar la insuficiencia del confinamiento - crudamente desconsiderado- de la protección de la Seguridad Social en un pasaje depresivo, se ha inventado - es decir, descubierto a través del discurso jurídico - un concurso de normas que subsume en los arts. 14 o $24.1 \mathrm{CE}$ los problemas que, de otro modo, sólo encajarían en el troquel estricto o figura rectora del art. $41 \mathrm{CE}$. Se ha llegado, con poder persuasivo y resultados justos, a reformular o rehacer su planteamiento en unos términos que permitan trasladar la cuestión suscitada al campo de los derechos fundamentales que esos preceptos reconocen. El razonamiento empleado evoca un uso alternativo - tácito y entre líneas - de la legalidad fundamental y se asemeja al que el Derecho Penal utiliza para resolver los llamados conflictos aparentes de normas. Trayendo a capítulo los derechos fundamentales a la no discriminación - frente a las diferencias de trato privadas de una justificación objetiva y razonable - y a la efectiva tutela judicial, que invade o roza casi siempre los dominios de la legalidad ordinaria, se abren sendas en que una reconversión o puesta en orden de los intereses debatidos suministra la cobertura óptima del derecho a la Seguridad Social. La protección - inviable con base en el principio del art. $41 \mathrm{CE}$ - facilita el equipaje de las garantías que, sobre todo en punto al recurso de amparo, adjudica a los derechos fundamentales y a las libertades públicas el art. 53.2 CE. 
Se ingiere una consideración de última hora. Una aportación del texto constitucional europeo - aniquilado por falta de ratificación unánimeconsistía en incorporar la CDFUE (Carta de los Derechos Fundamentales de la Unión Europea), que - bajo el título de Solidaridad y reiterando la lista de los consabidos derechos sociales - les confiere, incluido el derecho a la Seguridad Social, el título de derechos fundamentales cuyos contenidos centrales describen los arts. 87 a 94 TCUE. Estos preceptos reconocen los derechos a la información y consulta de los trabajadores en la empresa, a la negociación colectiva y a la acción sindical, al acceso a los servicios de colocación, a la protección contra los despidos injustificados, a la prestación de trabajo en condiciones equitativas y justas, a la prohibición del trabajo infantil y la protección de los jóvenes en el trabajo, a la coordinación de la actividad profesional y la vida familiar y, en fin, a la Seguridad Social, que ya lo era merced al anterior razonamiento que ahora se recupera y rehabilita.

La tesis que, tras el descarrilamiento del TCUE, revive y recobra su razonabilidad, deja indemne la atribución al derecho a la Seguridad Social - junto con los demás derechos sociales mencionados - del carácter de derecho fundamental en el ámbito social europeo. Lo cual no significa que, por obra de una súbita conversión o acto de fe, los poderes públicos de los Estados miembros - más bien devotos de los prejuicios economicistascomulguen, afanosamente y de buen grado, con estas conclusiones.

Es claro que - en sana puridad democrática - la no ratificación del TCUE, procedente de la opinión popular directamente consultada, equivale a una manifestación de voluntad definitiva o negativa irreversible que agota esa oportunidad, sin que se pueda subsanar ni corregir - en busca de una unanimidad anómala y tardía- promoviendo, dentro del procedimiento ya herido de muerte, una ulterior ratificación parlamentaria.

\section{Renacimiento de una anterior doctrina}

La posición es defendible desde que el art. 136 I VCTR (Versión consolidada del Tratado de Roma, modificado por el TA (Tratado de Ámsterdam de 20.10.(9)97)) dio nueva redacción al art. 117 I VATR (Versión anterior del Tratado de Roma de 25.05.(9)57), que - pese a la debilitación semántica de algunas de sus versiones nacionales - conservaba una cláusula de corte igualitario, cuya intencionalidad y energía recordaban la inspiración de los arts. 3 II CI (Constitución italiana de 27.12.(9)47) y 9.2 CE. De acuerdo con el art. 1.12 TA, esa orientación — encaminada a la igualación en el progreso venida de la mejora de las condiciones de vida y de empleo de los trabajadores en los Estados miembros - se completa 
con el compromiso de dos proposiciones esenciales para iluminar el semblante de una Europa Social que, sin veladuras ni disfraces, comunica su voluntad de ser tal. Una de ellas señala que, entre otros objetivos, la UE y los Estados miembros perseguirán el consistente en una adecuada protección social. La otra indica que, con el mismo fin, emprenderán acciones de exploración y vigilancia de la diversidad de las prácticas nacionales al respecto. Precisiones de máximo rigor y que, a la hora de cimentar el sector del ordenamiento jurídico europeo de la Seguridad Social, llevan a pensar de dos modos. O bien esas prácticas afianzan la firmeza de las orientaciones comunitarias y aceleran su consolidación, porque se ajustan de antemano al espíritu y finalidad del Derecho de Gentes que hay que construir - sin dilaciones ni lagunas - para liquidar las promesas crípticas y las divagaciones especulativas sobre un futuro que, aunque se dice estar tocando con la mano, parece inaprehensible. $\mathrm{O}$ bien - ante unas prácticas nacionales corregibles o menos elogiables - se denuncia su irrazonabilidad o su injustificado arbitrismo, porque conculcan la universalidad de los principios informadores del depósito de los derechos sociales, en general, y, en particular, del derecho a la acción protectora de la Seguridad Social. Pautas que, según el art. 137.3 mat. (materia)1 VCTR, forman parte del componente normativo que, a propuesta de la ComUE (Comisión de la Unión Europea) y previas las consultas del caso, debe el ConUE (Consejo de la Unión Europea) rehacer - por unanimidad - para constituir la Seguridad Social de los trabajadores.

Este discurso y las reflexiones que le acondicionan, eran provisionales mientras se predecía el resultado favorable que - a juzgar por el optimismo de las cábalas y el presumible asentimiento de los Estados miembros - cerraría con éxito el procedimiento aprobatorio del TCUE. Nadie intuía un insalvable atolladero del trámite de conformidad que - por vía de democracia directa o delegada - comprendía la ratificación unánime de los países signatarios, que, sin excepciones, requiere el art. 447 TCUE. El tít. IV, part. (parte) II TCUE confería - como ha quedado dicho - a los derechos sociales la condición de derechos fundamentales y su terminante sistematización tenía que suceder a una interpretación que, por obra y gracia de la falta de unanimidad, no se desecha, sino que permanece. Lo inviable de la unanimidad - causada por episodios que, a estas alturas, evidencian la dosis de conciencia europea de los Estados soberanos que han denegado o diferido sus declaraciones de coasentimiento - resucita el estado de cosas defendido con la argumentación que ha empezado a exponerse y debe conservarse.

Hay que destacar, volviendo al discurso interrumpido, la importancia renacida de la toma de posición que justifica el art. 136 I VCTR. $\mathrm{El}$ art. 2.58 TA finaliza la operación depuradora consistente en cancelar 
la situación desconcertante y surrealista que - merced a una cómoda transigencia política y un falso espíritu de consenso - le había precedido. Deroga el Prot. PS (Protocolo relativo a la Política Social) y el APS (Acuerdo sobre Política Social adjunto al Prot.PS), que, cercenados de la parte dispositiva de la VATUE (Versión anterior del Tratado de la Unión Europea de 7.02.(9)92), alojaban —en régimen de vagancia vergonzante- unas consignas de Política Social cuya plenitud y pulcritud académicas chocaban con la esterilidad jurídica de su posición sistemática. El inicio del Prot.PS pregonaba el escueto deseo - mucho menos que la voluntad programática y alejado, años luz, de la eficacia preceptiva directa- de aplicar, a partir del acervo comunitario o, lo que es lo mismo, del bloque de constitucionalidad europeo para cada materia, la CCDFST (Carta Comunitaria de Derechos Sociales Fundamentales de los Trabajadores de 8 y 9.12(9)89), sin preocuparse, lo más mínimo, de fortalecer la irrevocabilidad y el arraigo de las situaciones jurídicas que este documento define, ni adelantar iniciativas aptas para desvirtuar lo heterogéneo de su texto de compromiso.

El art. 136 I VCTR - que impone a la Comunidad y a los Estados miembros el objetivo de instaurar una protección social adecuada ¿̇a qué intereses, finalidades, utilidades, necesidades, conveniencias y, en general, estados de cosas?) - declara que, al actuar en pro y en pos de lo que este concepto jurídico indeterminado significa, se han de tener presentes los derechos sociales fundamentales enunciados en la CSE (Carta Social Europea de 18.10.(9)61) y los que, al mencionar los derechos sociales fundamentales de los trabajadores, reconoce la CCDFST. La remisión que así se hace, delimita el más reciente contenido del Derecho fundamental comunitario - cuya versión y validez jurídica retornan tras el irrevocable revés electoral del TCUE - y diseña el derecho a la acción protectora de la Seguridad Social como un derecho fundamental provisto de cuantos atributos le acompañan en calidad de tal. De ahí, las obligaciones estatales de emprender las reformas constitucionales procedentes y enmendar una distribución reñida con el carácter adjudicado a estos derechos por la naturaleza de las cosas y no por el arbitrio - variable y movedizo - de una cambiante voluntad política. El art. 136 I VCTR demuestra - con el valor dogmático de su envío a textos anteriores que, una vez positivizados, gozan del vigor que nunca debió desasistirles - que, además de los otros derechos que enumera, el derecho a la Seguridad Social de los trabajadores es un derecho fundamental. Dictamen de la razón teórica con que opera el constituyente europeo - después de congelarse la mejora absoluta que el tít. IV, part. II TCUE reservaba a la suerte de los derechos sociales - y que, ante las admoniciones inmediatas de la razón práctica, explica el acierto de la calificación defendida. 


\section{Aplicación del principio de primacía del Derecho Comunitario}

Se ha malogrado el empeño en concluir con éxito un proceso constituyente que, además de serlo formalmente, probaría el asentimiento reflexivo y no desinformado de los pueblos de los Estados soberanos llamados a ratificar el TCUE. Renace, para colmar una laguna que no se puede eternizar, la asignación del carácter fundamental que corresponde a los derechos sociales europeos. Ante el sesgo imprevisto de los acontecimientos, cabe que la remisión del art. 136 I VCTR - activa de nuevo en ese campo- no se tome en consideración, preponderando el hábito de la sordera endémica $\mathrm{o}$ la caída en saco roto, o que, improbablemente, se reconozca el carácter fundamental del derecho a la Seguridad Social y se le traslade al pasaje rubricado De los derechos fundamentales y de las libertades públicas, que le pertenece y que encabeza la sec. $1 .^{\text {a }}$, cap. $2 .^{\circ}$, tít. I CE. Omitir este deber de adaptación y olvidarse del procedimiento de reforma que fijan los arts. 87.1 y 2, y 168.1 CE, no quiere decir que las conclusiones defendidas dejen de surtir los efectos técnico-jurídicos que su aplicación determina.

Es entonces cuando el principio de primacía del Derecho Comunitario tiene que intervenir. Su tenor da a entender - como variante o diversión del clásico principio de jerarquía normativa - que, con independencia de su rango, las reglas jurídicas emanadas de los órganos comunitarios competentes para generarlas, prevalecen sobre las que -destinadas por los Estados miembros a ordenar instituciones homólogas, análogas o afinesvulneran las normas superiores del depósito del Derecho fundamental - constante, hasta el momento, en los Tratados sucesivos - y del Derecho derivado que surge del desarrollo del primero. Lo maleable del espíritu y la finalidad del principio se movilizan ante el problema debatido, porque la primacía del Derecho Comunitario va más allá de la superioridad excluyente o el imperio de las normas jurídicas europeas sobre las disposiciones estatales, que, si les son incompatibles, tienen que inaplicarse, cuando menos, a la situación controvertida, si no hay mecanismos directamente destinados a expulsar del ordenamiento jurídico del Estado la norma de rango inferior que motiva la contradicción.

La primacía del Derecho Comunitario no se ciñe al control del contenido dispositivo de las relaciones de jerarquía normativa en el seno de una materia o institución determinada, sino que también toca a la naturaleza - que, al identificarla, le confiere igualdad consigo misma- y a los perfiles axiológicos de su calificación. El Derecho objetivo de los Estados miembros no puede, so pena de violar ese principio, rebajar la dignidad ni mudar la naturaleza jurídica de una institución que -como aquí sucede con el derecho a la Seguridad Social-las normas comunitarias recobradas diseñan más esmeradamente y a la que - por vía de hallazgo y 
especificación de sus rasgos de identidad-atribuyen superior condición o dotan de una tutela más intensa que la que simultáneamente le conceden la legalidad constitucional o la legislación ordinaria del Estado.

Hace falta que, ante contradicciones tan palpables, el Estado miembro - cuya legislación debe enmendarse para eliminar la vulneración denunciada - reforme los oportunos extremos del sector correspondiente del ordenamiento jurídico y restaure la adecuación pendiente de efectuarse. Si deja de hacerlo y omite - como ocurre con alguna frecuencia - sus deberes de Estado-legislador, la distinción concedida por el ordenamiento jurídico comunitario al derecho a la Seguridad Social no se paraliza ni queda sin efecto. Por algo el mandato del art. 9.2 CE está en primera línea y nunca muere la confianza puesta en su realidad y efectividad transformadoras. Su cláusula se impone a todas y cada una de las instancias y poderes públicos que, partiendo de esa sujeción, quedan vinculados por lo que, lejos de un caprichoso cambio de etiqueta, es la última palabra que, de momento, puede decir y está diciendo el Derecho fundamental comunitario. La condición fisionómica que - hoy por hoy y no a la luz del tít. IV, part. II TCUE, sino del estado de cosas que suple la imposibilidad jurídica de una ratificación unánime de los Estados miembros de la UE antes de 1.11.06 - adquiere el derecho a la protección de la Seguridad Social, sigue obligando a esos países que, en el caso de haberse logrado la deseada, se someterían a lo dispuesto en los arts. 440.1, 446 y 447.2 TCUE.

Deben, conforme a la legalidad resucitada y vigente, disponer lo preciso para que el Derecho del régimen público de la Seguridad Social obtenga, sin tardanza ni excusa, el tratamiento de un derecho fundamental nacido de una solidaridad sabiamente entendida y expresiva - como reza el Pr.(Preámbulo) CDFUE-de un valor insito en el bloque - universal e indivisible - de la dignidad, la libertad y la igualdad de la persona humana, que ocupa el centro de un espacio de seguridad y de justicia.

¿Qué ha de esperarse de la tercera vía que, como versión difusamente divulgada, evoca, no menos nebulosamente, ciertos compromisos históricos del Estado de Bienestar y dice aspirar a que la Política de las relaciones de trabajo y de la Seguridad Social deje de ser la pariente pobre y menos venerada de cuantas pueblan la tierra prometida de la Europa Social? ¿No son los autores de esta predicción enigmática - a juzgar por su talante personal y por los testimonios históricos de su puesta en escena- los menos indicados para hacer de su augurio algo distinto del cambio de etiqueta que, gracias a sus habilidades persuasivas, produce el efecto adormecedor de las promesas hechas para no ser cumplidas?

Las lecturas originalista y evolutiva que, siempre a través de un uso alternativo constitucional, tolera el artículo 41 de la Constitución - norma de acción concerniente al derecho fundamental en que se ha transformado su principio- dependen, en mucho, de las consideraciones expuestas hasta aquí. 